\title{
Impuestos a los juegos de apuesta y principios constitucionales tributarios
}

\section{Carlos Alberto Fonseca Sarmiento}

Abogado por la Universidad de Lima. Magíster en Derecho Constitucional por la Pontificia Universidad Católica del Perú. Máster en Administración Pública por el Instituto Ortega y Gasset de Madrid.

SUMARI0:

I. Introducción.

II. ¿Qué son los juegos de apuesta?

III. ¿Es una actividad lícita en el Perú?

IV. Clasificación de los juegos de apuesta.
1. Los juegos de casino.
2. Las máquinas tragamonedas.
3. Las loterías.
4. Las apuestas sobre carreras de caballos.
5. Otros juegos de apuestas presenciales.
6. Los juegos de apuestas online.

V. La Potestad Tributaria y los Principios Constitucionales Tributarios.

1. La Potestad Tributaria.

2. El Principio de Reserva de Ley.

3. El Principio de Igualdad.

3.1. Principio de Igualdad ante la Ley.

3.2. Principio de Igualdad en la Ley.

4. El Principio de No Confiscatoriedad.

4.1. Confiscatoriedad cuantitativa.

4.2. Confiscatoriedad cualitativa.

VI. Los impuestos a los juegos de apuesta en el Perú.

1. La prohibición de impuestos a las ganancias brutas y el Impuesto a los juegos de casino y máquinas tragamonedas.

2. La naturaleza tributaria de los pagos forzosos de los operadores de los juegos de lotería.

3. Violación de los principios de reserva de ley, de igualdad y efectos confiscatorios en el impuesto a las apuestas hípicas y similares.

4. Las ambigüedades del impuesto municipal a los juegos.

5. Los errores del Impuesto Selectivo al Consumo a los juegos de azar.

VII. Conclusiones. 


\title{
RESUMEN:
}

En el presente artículo el autor analiza las deficiencias detectadas en la legislación tributaria sobre los juegos de apuesta en base a los principios tributarios recogidos en el artículo 74 de la Constitución. El autor elabora un concepto y clasificación de los juegos de apuesta en función de sus características técnicas y su regulación en el Perú. El autor recomienda homogenizar la tributación sectorial de los juegos de apuesta mediante la creación de un único impuesto y utilizando la misma metodología.

Palabras clave: Principios tributarios, reserva de ley, igualdad, no confiscatoriedad, juegos de apuesta, máquinas tragamonedas y loterías.

\begin{abstract}
:
In this article, the author analyzes the deficiencies detected in the tax legislation on gambling based on the tax principles set forth in article 74 of the Constitution. The author develops a concept and classification of gambling based on their technical characteristics and their regulation in Peru. The author recommends homogenizing the sectoral taxation of gambling by creating a single tax and using the same methodology.

Keywords: Tax principles, reserve of law, equality, non-confiscation, gambling, slot machines and lotteries.
\end{abstract}

\section{INTRODUCCIÓN}

En estos últimos años, los juegos de apuesta han tenido un desarrollo vertiginoso en todo el mundo. El dinamismo, la dependencia a la tecnología y la internacionalidad son factores relevantes de esta actividad. Cada vez hay más países interesados en regular esta industria. Muchas razones son invocadas: aumento de la oferta laboral, reducción de los efectos nocivos del juego al estar controlado, protección a los usuarios, desarrollo de infraestructura turística, mejoramiento de sectores desatendidos, etc. Sin embargo, hay una que siempre estará en cualquier modelo regulatorio asociado a esta actividad: la creación de impuestos. La receta será económicamente exitosa cuando los ingresos sean significativamente mayores a los costos de fiscalización y será jurídicamente legítima cuando sean exigidos dentro los límites de la Constitución.

Sobre este segundo punto se han reparado graves problemas, causados por la complejidad técnica de la actividad y los prejuicios que algunas autoridades presentan contra esta industria, los cuales provocan muchas veces restricciones irrazonables a los derechos fundamentales de los actores involucrados - empresarios, trabajadores y jugadores - lo que ha generado permanentes conflictos requiriendo la intervención del Poder Judicial o el Tribunal Constitucional.
$Y$ este fenómeno no es privativo del Perú. En Latinoamérica, en los últimos años, hemos sido espectadores de una abundante actividad de jueces constitucionales para resolver conflictos entre autoridades y empresarios en torno a la tributación de los juegos de apuesta, causando no pocas veces la inaplicación de leyes. Algo debe estar ocurriendo con nuestras legislaciones. Es imposible que los Poderes Judiciales y Tribunales Constitucionales de la región estén en pie de guerra contra las políticas públicas sobre juegos de apuestas implementadas. Esta situación nos motiva a analizar nuestra propia legislación tributaria y descubrir todos los vicios constitucionales que continúan existiendo al excederse de los límites fijados por los principios tributarios reconocidos por nuestra Constitución.

\section{II. ¿QUÉ SON LOS JUEGOS DE APUESTA?}

Los juegos son actividades sujetas a reglas cuyo propósito principal es constituir un pasatiempo para quien lo realiza. Son de apuesta cuando las reglas exigen a los participantes la obligación de arriesgar una cantidad de dinero $u$ otro bien económicamente valorable como condición para jugar. Además, el resultado de estos juegos genera obligaciones y derechos a sus participantes - por ejemplo, el ganador recibe un premio o el perdedor se queda sin el dinero arriesgado-. Los juegos de apuesta son jurídicamente relevantes pues hay un interés público 
derivado del dinero involucrado por los usuarios. El interés público se encuentra en garantizar las reglas imparciales y transparentes del juego, en el interés fiscal por la capacidad contributiva exhibida por los jugadores o en reducir cualquier riesgo social que pudiera provocar su práctica.

Los juegos de apuesta usualmente se clasifican, por el grado de intervención del participante en su resultado, en dos categorías: pueden ser preponderantemente de azar o de habilidad. Utilizamos la palabra "preponderantemente" porque la tecnología, en algunos casos, borra los límites claros entre estas dos categorías.

Son de azar aquellos cuyo resultado está determinado principalmente por circunstancias imprevistas e inevitables sobre las que los jugadores no tienen control y van a ser esenciales para el resultado final. Por ejemplo, en la ruleta, el resultado final depende del casillero numerado donde la bolita se detendrá luego de haber sido girada la rueda horizontal, por el representante - dealer- del casino. Ningún jugador tiene el control del movimiento de la bolita y nadie puede tener certeza del casillero donde se detendrá.

Son de habilidad aquellos cuyo resultado depende principalmente de la capacidad física o intelectual del jugador. En estos casos, el participante si tiene la posibilidad de controlar las variables del juego, haciendo uso de sus fortalezas, inteligencia y técnica. Por ejemplo, si los contrincantes en una partida de ajedrez apuestan, la mayor destreza de uno de ellos determinará al ganador.

Desde el punto de vista jurídico, es irrelevante si el resultado depende del azar o de la habilidad. Lo determinante es la existencia de una apuesta. Si hay dinero del público comprometido en el funcionamiento de un juego, no interesa como se determina el resultado, pues sea de azar o habilidad, la legislación aplicable establecerá las reglas para que el juego se realice con imparcialidad y transparencia y no se afecte la confianza del público.
Hay dos elementos adicionales y característicos de los juegos de apuesta: la pluralidad y la competencia. Para que un juego sea jurídicamente relevante es necesario contar con al menos dos personas. Los juegos individuales, en la medida que son realizados y sus efectos recaen en una sola persona, no generan interés público. Por otro lado, el juego siempre tiene que ser de competencia. Esto ocurre si el juego produce un efecto en la situación de sus participantes, por ejemplo, declarándolos ganadores o perdedores. Si el juego es sin competencia y se realiza por el mero pasatiempo, no origina ningún cambio en el estatus jurídico de los jugadores y por lo tanto es intrascendente para la ley.

Cuando los juegos de apuesta se realizan de manera empresarial aparece la figura del "Operador": aquel sujeto que organiza el juego de apuesta y en virtud de quien pueden existir juegos de contrapartida, cuando el operador se enfrenta a uno o más jugadores; o juegos de círculo o juegos cruzados, cuando los jugadores se enfrentan entre sí y el operador como coordinador y garante del juego recibe una comisión de las apuestas efectuadas.

La actividad del operador genera interés público pues produce una relación asimétrica con sus consumidores, revela una exteriorización de capacidad contributiva, pues el público destina dinero en una actividad de ocio que no satisface necesidades básicas y puede provocar externalidades negativas a la sociedad. Este genera costos de regulación y fiscalización para el Estado quien usualmente realiza el control a través del otorgamiento de licencias y cubre el presupuesto de esta actividad estatal mediante impuestos especiales.

Dicho esto, podemos definir a los juegos de apuesta como aquella actividad de entretenimiento en la que participa más de una persona, donde los participantes arriesgan dinero $u$ otro bien económicamente valorable, que se encuentra sujeto a reglas que generan obligaciones y derechos y como consecuencia de su resultado, se determinan ganadores o perdedores.

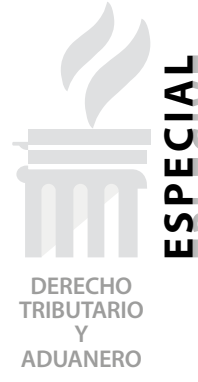




\section{III. ¿ES UNA ACTIVIDAD LÍCITA EN EL PERÚ?}

Nuestra actual Constitución Política, vigente desde 1993, contiene 4 artículos relevantes para determinar si es posible o no ofrecer juegos de apuesta en el Perú. Estos son los artículos 2, numeral 24 , inciso a) $)^{1}, 58^{2}, 59^{3}$ y $62^{4}$ :

El régimen económico de la Constitución tiene su columna vertebral en la libre iniciativa privada y en consecuencia toda actividad económica está permitida a menos que una ley impida su desarrollo. En otras palabras, para ofrecer juegos de apuesta en el país no es necesario "legalizar" la actividad sino sólo cumplir con cualquier regulación requerida de manera general, salvo que una ley especial disponga requisitos adicionales - por ejemplo, la obtención de un título habilitante-y el pago de impuestos adicionales a los generales.

Actualmente no existe una ley donde se regule de manera integral y coherente la provisión de juegos de apuestas en el territorio peruano. Por el contrario, existe una dispersa regulación sin ningún criterio técnico, provocando excesivas regulaciones para algunos juegos - por ejemplo, las máquinas tragamonedas-y laxas para otros - por ejemplo, las apuestas online-. Sin embargo, cualquier juego de apuesta puede ser operado empresarialmente en el país excepto cuando exista una ley expresa proscribiendo su desarrollo, la cual deberá estar debidamente justificada. Actualmente, solo dos juegos de apuesta están expresamente prohibidos. La explotación del juego de las carreras de perros, en virtud de una ley muy antigua, la Ley 10293 de 1945; y, la explotación de máquinas tragamonedas "que, por sus características o presentación, la Dirección General de Juegos de Casino y Máquinas Tragamonedas del Ministerio de Comercio Exterior y Turismo determine que se encuentran destinadas al juego de menores de edad", conforme lo prescrito por la Ley 29149 de 2007. ${ }^{5}$

\section{CLASIFICACIÓN DE LOS JUEGOS DE APUESTA}

Hacer una clasificación técnica de los juegos de apuesta es una tarea complicada justamente por uno de sus rasgos: su dependencia a la tecnología, la cual siempre está en permanente evolu-

1. Principio de Libertad -Artículo 2, numeral 24, inciso a)-:

"Toda persona tiene derecho: 24. A la libertad y a la seguridad personales. En consecuencia:

a. Nadie está obligado a hacer lo que la ley no manda, ni impedido de hacer lo que ella no prohíbe.

2. Principio de Libre Iniciativa Privada para ejercer actividades económicas —Artículo 58-:

"La iniciativa privada es libre. Se ejerce en una economía social de mercado. Bajo este régimen, el Estado orienta el desarrollo del país, y actúa principalmente en las áreas de promoción de empleo, salud, educación, seguridad, servicios públicos e infraestructura".

3. Libertades económicas reconocidas en la Constitución —Artículo 59-:

"El Estado estimula la creación de riqueza y garantiza la libertad de trabajo y la libertad de empresa, comercio e industria. El ejercicio de estas libertades no deber ser lesivo a la moral, ni a la salud, ni a la seguridad públicas. El Estado brinda oportunidades de superación a los sectores que sufren cualquier desigualdad; en tal sentido, promueve las pequeñas empresas en todas sus modalidades".

4. Libertad de contratar - Artículo 62-:

"La libertad de contratar garantiza que las partes puedan pactar válidamente según las normas vigentes al tiempo del contrato. Los términos contractuales no pueden ser modificados por leyes u otras disposiciones de cualquier clase. (...)".

5. Esta Ley revela notorios defectos al legislar sobre un juego de apuesta. Resulta curioso por no decir incongruente, no definir el juego materia de la prohibición con elementos objetivos y en lugar de ello, tomar como elemento central a su destinatario - menores de edad- y en virtud de una decisión subjetiva que le corresponde a un órgano técnico normativo de línea de un Ministerio —es decir, ni a su máxima autoridad-. ¿Qué propiedades o cualidades debería presentar dicho juego para reconocer que no están destinados a los mayores de edad? 
ción. Esto hace cada vez más difícil establecer límites claros entre un tipo de juego y otro. Por ello, vamos a hacer un intento por clasificar a los juegos de apuesta en función no sólo del evento técnico que provoca su resultado, sino también por la forma como en el país se han regulado - o dejado de regular - tanto en el ámbito tributario como el de las licencias. De esta manera, podemos agruparlos en 6 categorías.

\section{Los juegos de casino.}

Están definidos en el artículo 4 inciso a) de la Ley 27153 de 1999, Ley que regula la Explotación de Juegos de Casino y Máquinas Tragamonedas, como: "Todo juego de mesa en el que se utilicen naipes, dados o ruletas y admitan apuestas del público, cuyo resultado dependa del azar, así como otros juegos a los que se les otorgue esta calificación de conformidad con la presente Ley".

Se caracterizan por ser "juegos localizados", es decir, requieren un establecimiento físico permanente - generalmente denominado casino o sala de juego- del operador, en donde se desarrolla todo el proceso del juego. En consecuencia, también son "juegos presenciales" pues el usuario tiene que asistir a dicho lugar para poder apostar. Son "juegos de interacción humana" pues para su desarrollo es necesaria la intervención de un representante del operador - el dealer - quien conduce el juego, sea este de contrapartida - por ejemplo, el blackjack, donde la "casa" compite contra los jugadoreso de círculo - por ejemplo, el póker americano, donde los jugadores compiten entre sí y la "casa" recibe una comisión por organizar el juego-. El resultado del juego está determinado por un evento aleatorio manual: el lanzamiento de los dados, el giro del disco de la ruleta o el barajo de naipes - aunque existen barajadores automáticos pero el dealer tiene que repartir las cartas-. Son de resultado inmediato, pues se hace la apuesta y el proceso de juego se inicia y se resuelve en el acto.

\section{Las máquinas tragamonedas.}

Están definidas en el artículo 4 inciso b) de la citada Ley 27153 de 1999, como: “Todas las má- quinas de juego, electrónicas o electromecánicas, cualquiera sea su denominación, que permitan al jugador un tiempo de uso a cambio del pago del precio de la jugada en función del azar y, eventualmente, la obtención de un premio de acuerdo con el programa de juego".

Las máquinas tragamonedas también son "juegos localizados", que al igual que los juegos de casino solo pueden funcionar en salas de juego autorizadas por el Ministerio de Comercio Exterior y Turismo. De igual modo son "juegos presenciales", pues el usuario tiene que estar sentado frente a la máquina para poder jugar. Son "juegos de interacción electrónica" donde el usuario sólo se interrelaciona con la máquina durante el proceso de juego. Generalmente son juegos de contrapartida pues el individuo compite con la "máquina" del operador, aunque la tecnología permite juegos de círculo - por ejemplo, hay máquinas tragamonedas de póquer americano-. El resultado del juego está determinado por un programa electrónico, aunque también existen máquinas tragamonedas de habilidad, cuyo desarrollo se basa también en un software, pero el resultado depende de la destreza del usuario. Esto sería un "videojuego de apuesta". Finalmente, son un juego de resultado inmediato, pues la decisión de si se ganó es al instante.

\section{Las loterías.}

Son juegos regulados por el Decreto Ley 21921 de 1977, expedido por el Gobierno Militar y posteriores normas modificatorias que incluyen al Decreto Legislativo 1411 de 2018 y Decreto de Urgencia 009-2020. Se encuentran bajo el ámbito de control del Ministerio de la Mujer y Poblaciones Vulnerables —en adelante, "MIMP"—.

Su marco legal tiene una extraña particularidad: carece de una definición normativa. Y no existe unidad conceptual respecto de este juego. Las imprecisiones se encuentren prioritariamente para determinar si la lotería es una especie, un concepto similar al de "sorteo" o abarcan a todo juego de apuesta cuyo evento definitorio es justamente el sorteo. Considerando todos los juegos que pueden estar alcanzados por este

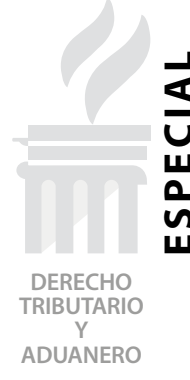

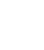


término, al menos como se entiende predominantemente en la industria, podríamos definir a la lotería como un juego de carácter colectivo y de naturaleza pública donde se determinan números o símbolos mediante sorteo, otorgándose un premio al titular del número, símbolo o combinación de éstos que hubiera sido extraído u obtenido de acuerdo con las reglas del juego. Entre las modalidades que pueden presentar podemos mencionar a la lotería de billetes, rifa, bingo, keno, lotería electrónica, tómbola, lotería presorteada o instantánea y videolotería.

Actualmente en el Perú estos juegos sólo pueden ser operados por las Sociedades de Beneficencia Pública - en adelante, "SBP" - lo cual es una barrera a la libre iniciativa privada. Podría sostenerse que las SBP no son "entidades del Estado" sino únicamente personas jurídicas de derecho público interno y por lo tanto no hay actividad empresarial del Estado, pero no obstante ello, lo razonable sería que cualquier empresa privada — cumpliendo las regulaciones especiales - pueda realizar esta actividad económica y no restringir su ejercicio a las SBP cuyas autoridades son designadas con la intervención del Estado y se crean por Ley.

Dicho esto, debemos señalar que algunos juegos de lotería son "localizados", por ejemplo, el juego del bingo, mientras que otros son "deslocalizados", por ejemplo, las loterías electrónicas cuyo sorteo no requiere de un establecimiento físico permanente. Son juegos "presenciales" porque el usuario tiene que acudir al establecimiento físico - el cual puede ser un módulo o kiosko inclusive- para hacer su apuesta y recibir la constancia del juego - billete, ticket, etc.- . Pero también existe la posibilidad de juegos "no presenciales" pues la tecnología permite adquirir un billete de lotería a través del internet. Generalmente son "juegos de interacción humana" pues la constancia de participar se recibe de un representante del operador al adquirir el boleto de juego; sin embargo, tanto por internet como en los propios establecimientos físicos pueden existir terminales automáticos de billetes de lotería sin la participación de un representante del operador. Son juegos de contrapartida pues se compite contra el operador.

El resultado del juego está determinado por el sorteo que alcanza a todos los participantes. El sorteo puede ser previo cuando se trata de una lotería instantánea - pues el resultado no visible del juego ya está en la tarjeta. Por último, los juegos de lotería se caracterizan por no ser de resultado inmediato pues generalmente los sorteos se hacen con frecuencia diaria o semanal, pero se tiene que respetar un plazo para que los participantes puedan adquirir sus boletos. No obstante ello, en juegos como la tómbola, el bingo, la lotería instantánea o el keno el resultado es inmediato.

\section{Las apuestas sobre carreras de caballos.}

Su regulación se sustenta en la Ley 15224 de 1964, la cual dispone en su artículo 2 que:

"Las carreras de caballos y las actividades del Stud Book, se regirán por los Reglamentos de Carreras, de Apuestas y del Stud Book del Jockey Club del Perú en la ciudad de Lima o el de la entidad organizadora del espectáculo en los Hipódromos de provincias, con excepción del Stud Book, que queda centralizado en el Jockey Club del Perú, debiendo sujetarse obligatoriamente a sus disposiciones los propietarios de caballos, los criadores de caballos y propietarios de Haras, los apostadores, los preparadores, jockeys, vareadores, y en general, todos los profesionales y todas las personas y entidades que tengan relación con las actividades hípicas".

Son apuestas sobre competencias - pugnas de velocidad-de caballos montados por un jinete - jockey-, las cuales se realizan en un recinto específico denominado hipódromo, por ello son "juegos localizados". Son "presenciales" pues el jugador tiene que estar en el hipódromo o en una agencia concesionaria de éste - usualmente denominada en nuestro país como "telepódromo" - para poder apostar. Generalmente son de "interacción humana" pues un representante del organizador es el que recibe el pago del boleto, pero también 
existen máquinas expendedoras electrónicas donde no ocurre esta interacción. Son "juegos de contrapartida" pues si ganan los jugadores, el operador responde por el pago; pero la principal modalidad del juego se denomina técnicamente "apuestas mutuas", donde los premios se distribuyen entre los jugadores ganadores en un porcentaje del total del dinero apostado en el juego y cuya determinación del porcentaje a distribuir se encuentra en el Reglamento del Juego, previamente establecido. La diferencia entre el total del dinero apostado y el porcentaje distribuido constituye la ganancia del operador. El evento que determina el resultado es uno de carácter físico, el orden de llegada de los caballos a la meta. Finalmente, el resultado del juego no necesariamente es inmediato pues el apostador puede adquirir su boleto de participación con anticipación a la carrera. Las apuestas sobre carreras de caballos son un espectáculo además de un juego. Muchas personas asisten al hipódromo para ver el evento sin apostar.

\section{Otros juegos de apuestas presenciales.}

La tecnología deja abierta a innumerable tipo de otras apuestas que no están contenidas en las categorías anteriores y actualmente no tienen ninguna regulación especial. A este grupo las denominaremos "otras apuestas presenciales". Son todos aquellos juegos de apuesta - distintos a los anteriores- que se realizan de manera personal por el usuario, en un establecimiento o "Punto de Juego" del operador -el cual generalmente no es el organizador del evento sobre el cual se apuesta-, en el que el usuario realiza una apuesta en dinero o susceptible de valorización económica y que le otorga la posibilidad de obtener un premio, de acuerdo a las reglas del juego. Son "juegos localizados", pues las apuestas se captan en el Punto de Juego del operador. Se consideran juegos de apuesta "presencial" pues se requiere acudir el Punto de Juego del operador para concretar la apuesta. Y como la variedad es grande, pueden ser de interacción humana o electrónica, de resultado inmediato o mediato y de contrapartida o de círculo. El evento que determina el resultado es uno desconocido por las partes y es un hecho real que puede ser físico - por ejemplo, el resultado de un partido de fútbol — o virtual — por ejemplo, el resultado de una carrera de galgos virtual.

\section{Los juegos de apuestas online.}

Tampoco cuentan con una regulación especial en el país, entonces carecemos de una definición normativa; sin embargo, podemos describirlos como todos aquellos juegos de apuesta desarrollados mediante un dispositivo de acceso remoto a internet - por ejemplo, una computadora, tableta o teléfono inteligente-, en el que el usuario realiza una apuesta en dinero o susceptible de valorización económica y que le otorga la posibilidad de obtener un premio, de acuerdo a las reglas del juego. Los juegos de apuesta online presentan dos modalidades: juego de internet y juego con internet. Los primeros son los que nacen, se desarrollan y concluyen en el internet - por ejemplo, las máquinas tragamonedas virtuales que aparecen en un sitio web-y los segundos, son aquellos que utilizan el sitio web para recibir la apuesta e interactuar con el jugador, pero el desarrollo y resultado obedece a un evento externo - por ejemplo, el de un partido de fútbol, como en el caso de los juegos de apuestas presenciales, donde la única diferencia es el canal, en uno de manera presencial y en este por internet-.

La principal característica de estos juegos es que son "deslocalizados". Con sólo tener el dispositivo de acceso remoto se puede jugar, sea cual sea el lugar donde físicamente se encuentre el usuario. Por lo tanto, son "juegos remotos" pues el usuario no tiene que estar en un establecimiento físico del operador para poder jugar, no obstante que en algunas jurisdicciones comenzaron a usarse las denominadas "cabinas de internet" como recintos para hacer apuestas online utilizando las computadoras que el propietario alquila a los usuarios. Son "juegos de interacción electrónica" pues el usuario sólo se interrelaciona con el dispositivo de acceso remoto durante el proceso de juego. Generalmente son "juegos de contrapartida", pues el individuo compite contra el operador; aunque la tecnología permite "juegos de círcu-

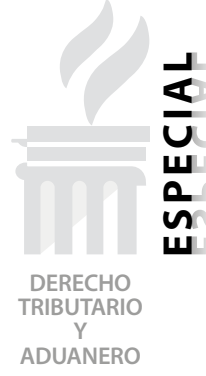

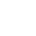


lo" donde el operador cobra una comisión del dinero jugado.

El resultado del juego está determinado por un programa electrónico que se encuentra en el servidor, en el caso de los juegos de internet, mientras que, en los juegos con internet, el resultado depende de un evento real - puede ser una competición real, por ejemplo, un partido de tenis entre Federer y Nadal o de una competición virtual, por ejemplo, cuando se apuesta en una competencia de e-sports-. Las apuestas online son un juego de resultado inmediato cuando son generalmente juegos de internet y de resultado mediato cuando son juegos con internet.

\section{LA POTESTAD TRIBUTARIA Y LOS PRINCI- PIOS CONSTITUCIONALES TRIBUTARIOS}

\section{La potestad tributaria.}

A rasgos generales, se entiende por potestad tributaria a la facultad que tiene el Estado de crear, modificar, suprimir o establecer la exoneración de tributos. Antiguamente, fue utilizado de manera ilimitada y arbitraria por el gobernante, pero con la aparición del constitucionalismo y el Estado de Derecho se sometió a las reglas y limitaciones contenidas en los preceptos constitucionales. El artículo 45 constitucional dispone: "El poder del Estado emana del pueblo. Quienes lo ejercen lo hacen con las limitaciones y responsabilidades que la Constitución y las leyes establecen". Este ejercicio de poder se realiza en distintos campos y bajo diversas reglas. Aquel que se lleva a cabo en el campo tributario recibe el nombre de potestad tributaria.

La potestad tributaria es una facultad exclusiva del Estado, pero dentro de su estructura generalmente existen varias autoridades con porciones determinadas de poder. En un Estado unitario pero descentralizado como el nuestro, por ejemplo, hay distintos niveles de gobierno. En estos casos, la potestad tributaria puede ser ejercida por varios órganos de poder. De acuerdo a nuestro marco constitucional, puede producirse una de estas modalidades:

a) Potestad Tributaria Inmediata: Cuando es ejercida por un titular de poder tributario únicamente con los límites y condiciones fijados en la Constitución.

b) Potestad Tributaria Mediata: Cuando es ejercida por un titular de poder tributario, pero con los límites constitucionales y los que le fije el titular de la potestad tributaria inmediata con competencia para delegarle esta facultad. Los límites y condiciones establecidos por el órgano con potestad tributaria inmediata al órgano con potestad tributaria mediata se efectúan a través del instrumento normativo idóneo para ejercer su potestad tributaria inmediata.

El artículo 74 de nuestra Constitución ${ }^{6}$ establece la regla general para el ejercicio de la potestad tributaria del Estado. Se reconoce potestad tributaria a cuatro órganos del Estado: el Congreso, el Presidente de la República, los Gobiernos Regionales y los Gobiernos Locales, al disponer lo siguiente:

"Los tributos se crean, modifican o derogan, o se establece una exoneración, exclusivamente por ley o decreto legislativo en caso de delegación de facultades, salvo los aranceles y tasas, los cuales se regulan mediante decreto supremo.

Los Gobiernos Regionales y los Gobiernos Locales pueden crear, modificar y suprimir contribuciones y tasas, o exonerar de éstas, dentro de su jurisdicción, y con los límites que señala la ley. El Estado, al ejercer potestad tributaria, debe respetar los principios de reserva de la ley, y los de igualdad y respeto de

6. Sin embargo, un exacto alcance de este concepto solo puede ser obtenido con la lectura complementaria de los artículos 56, 79, 118 numeral 20, 195 y 196 de la Constitución. 
los derechos fundamentales. Ningún tributo puede tener carácter confiscatorio. (...."."7

La ausencia de una definición de tributo puede generar incertidumbres y arbitrariedades. Para garantizar la seguridad jurídica, en una eventual reforma constitucional será recomendable contar con conceptos precisos de las tres especies tributarias: impuestos, contribuciones y tasas; identificándose la exacta porción de poder tributario respecto de ellas que corresponde a los distintos órganos estatales designados por la Constitución. La búsqueda de interpretaciones al borde del límite es una consecuencia de esta omisión. Por ejemplo, con la Sentencia del Tribunal Constitucional recaída en el Expediente $\mathrm{N}^{\circ}$ 03283-2007-AA sobre la naturaleza no tributaria de la Contribución al FONAVI. ${ }^{8}$

Los principios tributarios son para los contribuyentes, garantía de sus derechos fundamentales; y para el Estado, límites al ejercicio de su poder tributario. Al estar fijadas en la Constitución ostentan la máxima jerarquía normativa dentro del ordenamiento jurídico de un país y en consecuencia toda expedición de una norma con rango de ley o de inferior jerarquía debe efectuarse conforme a estos principios. La Constitución de 1993 recoge cuatro: (i) Reserva de Ley, (ii) Igualdad, (iii) No Confiscatoriedad y (iv) Respeto de los derechos fundamentales de la persona. Los principios tributarios son en realidad especificaciones en el campo tributario de la protección de determinados derechos fundamentales de los contribuyentes, principalmente los derechos de libertad, igualdad y propiedad, que son impactados usualmente por el ejercicio del poder tributario. El último principio citado, denominado de "respeto de los derechos fundamentales" no es particular del poder tributario. En general, todo ejercicio de poder exige reverencia a los derechos constitucionales de las personas, así que solo nos concentraremos en los tres primeros.

\section{El principio de reserva de ley.}

También se lo conoce como Principio de Legalidad en materia tributaria y se considera una de las bases sobre las que se estructura el derecho tributario en general. Constituye una precisión en el ámbito tributario de aquel derecho fundamental de toda persona consagrado en el artículo 2, numeral 24, inciso a) de nuestra Constitución, el cual prescribe: "Nadie está obligado a hacer lo que la ley no manda, ni impedido de hacer lo que ella no prohíbe". Por este principio debe entenderse que la facultad del Estado de crear, modificar, suprimir o establecer la exoneración de un tributo sólo está reservada a la "Ley"; entendiéndose por "Ley" para estos efectos a toda categoría normativa por la que conforme a la Constitución se puede ejercer la potestad tributaria. Los instrumentos normativos habilitados constitucionalmente para el ejercicio de la potestad tributaria y que por lo tanto deben considerarse "Ley" para este propósito, son los siguientes:

a) La Ley del Congreso de la República, para cualquier tributo.

b) El Decreto Legislativo del Poder Ejecutivo, para cualquier tributo establecido de acuerdo a las materias delegadas por la Ley autoritativa.

c) El Decreto Supremo del Poder Ejecutivo, para las tasas del gobierno central y los aranceles.

d) La Ordenanza de los Gobiernos Locales: Para sus contribuciones y tasas.

e) La Ordenanza de los Gobiernos Regionales: Para sus contribuciones y tasas.

7. Texto vigente según la modificación introducida por el artículo único de la Ley 28390, publicada el 17 de noviembre de 2004 en el diario oficial El Peruano.

8. Con el propósito que se pueda hacer un referéndum sobre la Contribución al FONAVI, creada por el Decreto Ley 22591 de 1979, en su Sentencia 03283-2007-PA/TC, el Tribunal Constitucional interpretó que tal aporte obligatorio no constituía un tributo y de esta manera removía el impedimento de llevar a cabo dicho referéndum, pues el artículo 32 de la Constitución no lo autoriza respecto de normas de carácter tributario. Con ello se modificó la interpretación predominante en la doctrina y la anteriormente sostenida por el Tribunal Constitucional en su Sentencia 001-1999-AT/TC, según la cual, este ingreso era un tributo. 
Se viola entonces este principio cuando:

a) Otra autoridad del Estado distinta a las anteriormente indicadas establece un tributo. Ejemplo: las tasas creadas por una Institución Pública Descentralizada mediante la norma de mayor jerarquía de dicha institución.

b) Cuando una de las autoridades con poder tributario crea un tributo que no es de su competencia. Ejemplo: el Gobierno Local que crea un Impuesto.

c) Cuando un órgano con poder tributario hace uso de éste mediante una categoría normativa inadecuada. Ejemplo: el Poder Ejecutivo crea una tasa mediante Resolución Ministerial.

d) Cuando un órgano con poder tributario crea un tributo con la categoría normativa idónea, pero sin incluir todos los elementos esenciales de la obligación tributaria. Ejemplo: el Congreso crea un impuesto, mas no su alícuota, la cual se crea por Decreto Supremo.

En efecto, si el principio exige que el tributo esté reservado a "Ley", entonces todos los elementos de la hipótesis de incidencia deben ser establecidos por la categoría normativa competente. En otras palabras, no debe dejar duda al momento de crearse un tributo sobre lo siguiente: acreedor tributario, deudor tributario, hecho generador de la obligación tributaria, base imponible y alícuota del mismo, el momento en que esta nace y el ámbito espacial en que se aplica. Si no indicara estos elementos, habría vulnerado este principio y por lo tanto sería inconstitucional. Respecto a un principio constitucional no se puede condescender, se cumple o se incumple.

\section{El principio de igualdad.}

Este principio puede resumirse en dos conceptos: Igualdad ante la Ley e Igualdad en la Ley. A continuación, los desarrollamos.

\subsection{Principio de Igualdad ante la Ley.}

En esta primera acepción, el principio constitucional tributario de igualdad es una especifi- cación en el campo tributario del derecho fundamental establecido en el artículo 2, inciso 2 de nuestra Constitución, que prescribe: "Toda persona tiene derecho: a la igualdad ante la ley. Nadie debe ser discriminado por motivo de origen, raza, sexo, idioma, religión, opinión, condición económica o de cualquier otra índole". También debe tenerse en cuenta lo previsto en el artículo 103 constitucional, el cual en su primer párrafo dispone lo siguiente: "Pueden expedirse leyes especiales porque así lo exige la naturaleza de las cosas, pero no por razón de la diferencia de las personas". En el ámbito tributario, este principio de Igualdad ante la Ley también recibe el nombre de Principio de Generalidad.

Este principio tiene un sentido positivo, el cual significa que todos los habitantes de un Estado están obligados a contribuir a su sostenimiento mediante el pago de tributos. Por cierto, esta generalidad de la obligación tributaria debe ser atemperada para su correcta definición. Significa esto que no todas las personas deben pagar tributos, pues sería injusto que se exigiera a aquellas personas que carecen de recursos económicos incluso para atender sus necesidades primarias. Por ello, aparece el concepto de "Capacidad Contributiva" como elemento esencial de todo tributo, en el entendido de que solo todo aquel que cuenta con aptitud de pago público debe contribuir al sostenimiento del Estado.

Por otro lado, el principio de generalidad tampoco significa que todas las personas con capacidad contributiva deban pagar todos los tributos instituidos por el Estado. Solo deben cumplir con aquellas obligaciones tributarias en las que tengan la condición de contribuyentes, es decir, cuando respecto a ellos ocurra el hecho generador del tributo previsto en la ley. Precisado de esta manera el principio, conviene advertir que los Estados no lo aplican rígidamente, pues usualmente es atenuado por las exoneraciones y beneficios tributarios en general fundados en la utilización de la tributación como instrumento de política económica y social. Entonces, si por un lado la Constitución consagra el principio de igualdad ante la ley; y por otro, las leyes disponen que algunas personas - de las que tienen capa- 
cidad contributiva - no cumplan con el pago de tributos, ¿no existiría una contradicción? Es por esa razón que debe tenerse mucha cautela con las exoneraciones, pues podrían volver inoperativo el principio de generalidad.

\subsection{Principio de Igualdad en la Ley.}

Es también conocido como Principio de Uniformidad. Constituye una garantía sustantiva y no meramente formal para los contribuyentes, pues limita el contenido de las normas expedidas por los titulares del poder tributario. En términos generales, significa que a situaciones iguales debe darse tratamientos tributarios iguales. Ello supone también, que en situaciones desiguales el tratamiento tributario no será el mismo. Es preciso hacer notar que con este principio no se impide a los titulares del poder tributario decidir tratos diferentes para determinados contribuyentes; por el contrario, esto sí está permitido, pero siempre $y$ cuando se funden en razones objetivas.

Las situaciones que deben ser analizadas para poder establecer si es razonable dar un tratamiento igual o desigual a los contribuyentes es el hecho generador de la obligación tributaria. Esto es, si del hecho generador resulta que pueden producirse situaciones distintas, lo lógico será aplicar tratos distintos. La manera como se aplica este principio en los impuestos es mediante la introducción de categorías de contribuyentes, estableciéndose a cada categoría de manera uniforme un mismo tratamiento tributario. Esta formulación del principio de igualdad en la ley en el ámbito de los Impuestos recibe el nombre de Principio de Capacidad Contributiva, enten- diéndose por tal, que el monto de los impuestos debe ser el mismo ante situaciones iguales de capacidad contributiva. En este contexto, el término "Capacidad Contributiva" no significa riqueza mínima que debe tener una persona para considerarla contribuyente - como en el Principio de Generalidad- sino elemento objetivo que identifica a un tipo de tributos. ${ }^{9}$

Este principio generalmente es el más afectado en la imposición a los juegos de apuesta. Tanto en comparación con otras actividades de entretenimiento como entre los mismos juegos de apuestas que se encuentran sujetos a impuestos distintos o al mismo impuesto, pero con tasas distintas provocando distorsiones en el mercado y afectando finalmente al usuario. Como señala Cabot:

“(...), si el juego es una forma de actividad de ocio que compite con otras actividades de ocio, como películas, discotecas y similares, entonces gravar los juegos más que sus competidores perturba el mercado competitivo. Los impuestos adicionales que paga la industria de los casinos se transfieren a los clientes en forma de costos más altos. Esto hace que el producto de juego sea menos competitivo que otros productos de actividades de ocio con los que compite por los clientes. Esto viola una doctrina de neutralidad en el sentido de que grava los productos básicos de manera diferente y afecta las decisiones de consumidores y productores. Como resultado, los ciudadanos se ven privados del derecho a elegir entre dos productos en competencia; en lugar de tener que aceptar el sustituto favorecido por la estructura tributaria. (....) $)^{n 0}$

9. En las tasas por ejemplo, no debería existir el Principio de Capacidad Contributiva como Uniformidad pues la cuantía es en función del servicio efectivamente prestado por el Estado; pero sí el Principio de Capacidad Contributiva como Generalidad para que aquel que carece de medios no pague las tasas.

10. Anthony Cabot, Casino Gaming. Policy, Economics and Regulation (Nevada: Trace Publications, 1996) 436-437. Es una traducción libre de lo siguiente: "(...), is a form of leisure activity that competes with other leisure activities such as movies, nightclubs, and the like, then taxing gaming more heavily than its competitors disturbs the competitive market. The extra taxes paid by the casino industry are passed on to the patrons in the form of higher costs. This makes the gaming product less competitive than the other leisure activity products against which it competes for customers. This violates a doctrine of neutrality in that taxes commodities differently and effects consumers and producers decisions. As a result, citizens are deprived of the right to choose between two competing products; instead having to accept the substitute favored by the tax structure (...)". 


\section{El Principio de No Confiscatoriedad.}

El derecho de propiedad está garantizado en nuestra Constitución en los artículos 2 inciso 16, y 70; sin embargo, este derecho no es absoluto pues debe ser ejercido en armonía con el bien común y el interés social. En síntesis, la propiedad debe cumplir una "función social". Al Estado le es permitido apropiarse legítimamente de una parte de la riqueza — propiedad — de los particulares por medio de la tributación, con el único objeto de cumplir con sus fines y promover las condiciones necesarias para el desarrollo de sus miembros y de la sociedad en general. Con el propósito de evitar que la tributación se convierta en un mecanismo indirecto de aniquilación de los derechos de propiedad de los particulares, nuestra Constitución prescribe que "ningún tributo puede tener efecto confiscatorio". Es una especificación en el campo fiscal de la protección del derecho de propiedad, en consecuencia, su interpretación debe establecer hasta qué punto la propiedad puede ser restringida por los tributos sin ser subvertida. Se hacen dos enfoques del efecto confiscatorio que puede revestir el pago de un tributo: desde el punto de vista cuantitativo y cualitativo.

\subsection{Confiscatoriedad cuantitativa.}

Se considera que un tributo tiene efecto confiscatorio en forma cuantitativa cuando absorbe una parte sustancial de la renta o el patrimonio del contribuyente. Para determinar que se entiende por "parte sustancial de la renta o patrimonio" no es conveniente establecer reglas fijas de carácter general, sino por el contrario, más acertado es analizar las circunstancias de hecho y la situación particular del obligado. En este sentido, será el criterio del Juez y no del legislador el que determinará cuando se configura la confiscatoriedad cuantitativa de un tributo, salvo que sea tan notorio que "le queme los ojos al juez" como fue el caso del impuesto a los juegos de casino y máquinas tragamonedas con la tasa del $20 \%$ de las ganancias brutas.

\subsection{Confiscatoriedad cualitativa.}

Desde el punto de vista cualitativo, se configu- rará cuando el tributo es exigido en colisión de cualquier otro principio constitucional tributario. Tal circunstancia acarrea la ilegitimidad del tributo constituyendo en un simple acto de despojo realizado por el Estado.

\section{LOS IMPUESTOS A LOS JUEGOS DE APUESTA EN EL PERÚ}

Lo primero que debe tenerse en cuenta es que la exteriorización de capacidad contributiva que justifica una imposición especial y adicional al régimen general se encuentra en el dinero destinado por los usuarios a los juegos de apuesta. No son necesidades básicas. Si bien está reconocido como derecho constitucional de toda persona, disfrutar del tiempo libre, también es legítimo que el Estado pueda ejercer su poder tributario respecto de aquellas personas cuyo tiempo libre lo destinan a satisfacer sus necesidades de ocio participando en juegos de apuesta.

Los operadores de estos negocios, como cualquier otro empresario, tienen que pagar un impuesto general por sus ganancias; pero como adicionalmente estas provienen de ese dinero excedente de parte de sus consumidores y con el propósito de proteger el interés público en esta actividad, el Estado incurre en costos de fiscalización que antes no los tenía, por lo que estos operadores pueden ser sujetos pasivos de un impuesto especial. El tema discutible entonces es cuál es la mejor técnica para establecer la imposición al juego. Generalmente, las decisiones que se toman para elegir el impuesto óptimo o más adecuado se basan en los criterios de claridad, equidad, costo administrativo y fines extrafiscales - efecto en el mercado-.

Actualmente en el Perú, existen 5 impuestos a los juegos de apuestas. No existe ningún criterio técnico para su creación. Son impuestos oportunistas con el único propósito de recaudar y sin reparar en los principios constitucionales tributarios antes mencionados. Al ejercer su potestad tributaria en este sector, nuestros gobernantes nos ofrecen un ejemplo gráfico de la Paradoja de Murphy: "Siempre es más fácil hacerlo de la forma más difícil". Hagamos un 
breve resumen de los actuales impuestos a los juegos de apuestas:

1. La prohibición de impuestos a las ganancias brutas y el Impuesto a los juegos de casino y máquinas tragamonedas.

Este impuesto fue creado por la Ley 27153 de 1999 y modificado por la Ley 27796 de 2002, como consecuencia de la inconstitucionalidad declarada a su versión original, mediante la Sentencia del Tribunal Constitucional recaída en el Expediente $\mathrm{N}^{\circ}$ 009-2001-Al.

Realmente es un impuesto a las ganancias brutas mensuales provenientes del juego; es decir, el monto total recibido por las apuestas menos el monto total entregado en premios durante el mismo mes y sin hacerse ninguna deducción vinculada a la generación de esa ganancia - por ejemplo, el arrendamiento del local, los salarios del personal, el pago del sistema de control online exigido por ley, etc.- - Tiene una tasa del $11.76 \%$. Sin embargo, para no calificarlo como un impuesto a las ganancias brutas, el legislador señala que la diferencia entre apuestas menos premios se llama "ingreso neto mensual" y existe un descuento del $2 \%$-la Ley lo denomina "gastos por mantenimiento" - sobre dicha base imponible, a la cual se le aplica la tasa del $12 \%$. Por eso la tasa efectiva del $98 \%$ de esas ganancias es el $11.76 \%$.

Los "gastos de mantenimiento" son absolutamente irreales. Sólo se colocaron con el fin de justificar que este no es un impuesto a las ganancias brutas. Pero las cosas son lo que fluye de su naturaleza y esencia, y no lo que arbitrariamente le denominen las partes. En este caso, es objetivo afirmar que del $100 \%$ de las ganancias brutas mensuales provenientes del juego que obtengan los operadores de juegos de casino y/o máquinas tragamonedas, deberán entregar al Estado a título de impuesto, el 11.76\% de dicha ganancia.

Este impuesto tiene como sujeto pasivo al que realiza la operación de los juegos de casino o las máquinas tragamonedas. Es un impuesto del Gobierno Central, el administrador tributa- rio es la Superintendencia Nacional de Aduanas y Administración Tributaria -en adelante, "SUNAT" - y se caracteriza por ser un impuesto de fines predeterminados, pues se distribuye de la siguiente manera: luego de descontar el $2 \%$ que corresponde a la SUNAT, el 30\% constituyen ingresos de las Municipalidades Provinciales en las que se ubiquen las salas de juego, el $30 \%$ constituyen ingresos de las Municipalidades Distritales donde se ubiquen las salas de juego, el $15 \%$ son ingresos del Tesoro Público, el $15 \%$ son ingresos del MINCETUR y el $10 \%$ son ingresos del Instituto Peruano del Deporte.

Aquí es necesario recordar lo establecido en el fundamento jurídico 16 de la referida Sentencia del Tribunal Constitucional 009-2001-AI/TC que declaró la inconstitucionalidad del Impuesto original cuya tasa era el $20 \%$ de la ganancia bruta:

"16. Estima el Tribunal que las especiales características del impuesto a los juegos, consideradas conjuntamente, hacen que este resulte confiscatorio y, por tanto, contrario al Artículo $74^{\circ}$ de la Constitución. En efecto: Si bien el artículo $36^{\circ}$ de la LEY establece que el impuesto a los juegos grava "la explotación" de estos juegos, conforme se desprende de la regulación conjunta de los Artículos 38.1 y 39 de la $L E Y$, la alícuota del impuesto asciende al 20\% de la base imponible "constituida por la ganancia bruta mensual... entendiéndose por ésta a la diferencia resultante entre el ingreso total percibido en un mes por concepto de apuestas o dinero destinado al juego y el monto total de los premios otorgados el mismo mes", esto es, que con el nombre o etiqueta de impuesto "a la explotación", la metodología impositiva de la ley grava en realidad a las utilidades. Considerando, además y conjuntivamente, que la alícuota del impuesto parece ser excesiva, que recae sobre una base fijada sin deducir los gastos realizados para la obtención de las utilidades y que no es considerado, el monto pagado como pago a cuenta del impuesto a la renta, debe concluirse que el gravamen presenta una vocación confiscatoria del capital invertido, prohibida por la Constitución" —el subrayado es nuestro-.

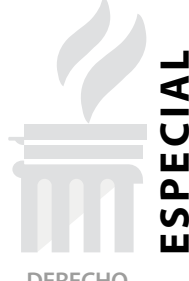

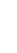


Como puede advertirse, para el Tribunal Constitucional, un impuesto a las ganancias brutas con una tasa del $20 \%$, que no permita deducir gastos vinculados y que no se permite usarlo como pago a cuenta del impuesto a la renta presenta vocación confiscatoria. El actual Impuesto a los juegos de casino y máquinas tragamonedas redujo la tasa del $20 \%$ al $12 \%$. Hemos dicho que "creó ficticiamente" una deducción de gastos por mantenimiento del $2 \%$ pero también permite su deducción del impuesto a la renta. Al final, sigue siendo un impuesto a las ganancias brutas, pero con una tasa más baja y que para efecto de la determinación de la renta bruta de tercera categoría permite su deducción. ¿Hasta qué punto se respetó la sentencia del Tribunal Constitucional? Lo que está claro es que una tasa del $20 \%$ sobre las ganancias brutas y $\sin$ deducciones es notoriamente inconstitucional y eso debería tenerse presente el legislador.

2. La naturaleza tributaria de los pagos forzosos de los operadores de los juegos de lotería.

Como se indicó, y contrario a un régimen de economía social de mercado, las únicas entidades que tienen el derecho de realizar esta actividad económica son las SBP. Pero como no están capacitadas financiera y empresarialmente para ello, lo hacen a través de operadores privados con quienes suscriben contratos de asociación en participación. El artículo 15, numerales 1 al 3, del Decreto Legislativo 1411 de 2018, dispone lo siguiente:

"15.1 Las Sociedades de Beneficencias están autorizadas, previa opinión técnica favorable del Ministerio de la Mujer y Poblaciones Vulnerables, a organizar juegos de lotería y similares, en este último supuesto no se consideran los juegos de casino, máquinas tragamonedas o juegos por internet y apuestas deportivas a distancia. Pueden hacerlo por si o contratando con personas jurídicas de derecho privado, en el marco de lo dispuesto en el Código Civil y en la Ley General de Sociedades, suscribiendo en este último caso el respectivo contrato de asociación en participación.
15.2 Las Sociedades de Beneficencia perciben no menos del $5 \%$ respecto a la venta bruta que genere el juego de lotería o similares, organizados a través de los contratos de asociación en participación.

15.3 El 1\% del porcentaje de la venta bruta que genere el juego de lotería y similares, es entregado al Ministerio de la Mujer y Poblaciones Vulnerables para ser distribuidos a favor de las Sociedades de Beneficencia que presenten planes de trabajo para optimizar sus servicios de protección social para el cumplimiento de su finalidad, siempre que no cuenten con recursos para su implementación; así como al Consejo Nacional para la integración de las Personas con Discapacidad - CONADIS, para la implementación de servicios de protección social, de acuerdo a lo establecido en la normativa vigente".

La naturaleza de estos pagos es discutible. La ausencia de un concepto constitucional de tributo genera este tipo de contingencias. Más polémico es el pago que recibe el MIMP, pues el contrato de asociación en participación se hace entre una SBP determinada y el operador que, por mandato de la ley, está obligado a un pago mínimo del 5\% de su venta bruta para recibir el privilegio de poder desarrollar este negocio. Pero el $1 \%$ de la venta bruta adicional que tiene que pagar el operador es para una entidad pública con la que no contrata. Es un pago forzoso que cumple con la definición de impuesto de la Norma Il del Código Tributario. Según esta norma, impuesto es el tributo cuyo cumplimiento no origina una contraprestación directa en favor del contribuyente por parte del Estado. En este caso, aquel que califique como operador está obligado a entregar el $1 \%$ de sus ventas brutas a la SBP, quien a su vez se lo traslada al MIMP. Con este Decreto Legislativo, el MIMP se convierte acreedor de ingresos brutos provenientes de estos juegos de apuesta. Conforme a nuestra Constitución, ¿no sería mejor que se permita a cualquier empresa a operar juegos de lotería con una licencia de juego otorgada por el MIMP y se establezca un impuesto? Finalmente, el Decreto Legislativo 1411 derivó de la Ley autoritativa 30823 de 2018, la cual otorgó 
facultades en materia tributaria muy específicas, entre las que no se encontraban crear un "impuesto encubierto a los operadores de juegos lotería".

\section{Violación de los Principios de reserva de ley, de igualdad y efectos confiscatorios en el Impuesto a las apuestas hípicas y si- milares.}

Es un impuesto creado por el Decreto Legislativo 776 de 1993, denominado Ley de Tributación Municipal, que grava las ganancias brutas ${ }^{11}$ de las entidades organizadoras de eventos hípicos "y similares", en las que se realicen apuestas. La frase "y similares" al constituir un texto vago incorporado en una ley que restringe derechos debe considerarse inoperativa al tener aplicaciones inestimables que afectan la seguridad jurídica. En efecto, al carecer de precisión suficiente el presupuesto de hecho que pudiera originar el pago de tributos se afecta el Principio de Reserva de Ley. Por otro lado, no hay que olvidar que es un impuesto a las ganancias brutas y no permite deducciones, por lo tanto, es a todas luces confiscatorio según el criterio adoptado por el Tribunal Constitucional en su Sentencia 009-2001-Al/TC. El sujeto pasivo es la institución que organiza estos espectáculos y se paga una tasa del $12 \%$ si son apuestas sobre carreras de caballos y $20 \%$ si son otras apuestas similares, pero de otro tipo de espectáculos. ${ }^{12}$ En el hipotético caso que pudiera ser legítimo exigir este impuesto a sujetos pasivos distintos a los organizadores de eventos hípicos, resultaría violatorio del principio constitucional de igualdad exigirles a estos una alícuota mayor del $20 \%$, más aún si ésta resulta notoriamente excesiva conforme a lo indicado por el Tribunal Constitucional.

\section{Las ambigüedades del impuesto munici- pal a los juegos.}

Es un impuesto también creado por el Decreto Legislativo 776 de 1993. Se caracteriza por sus imprecisiones. Su artículo 48 señala que "(...) grava la realización de actividades relacionadas con los juegos tales como loterías, bingos y rifas, así como la obtención de premios en juegos de azar (...)". Como hemos indicado anteriormente, no existe una definición legal de loterías, pero técnicamente su elemento central es el "sorteo" y por ello hay varias modalidades de este juego, entre las que se incluyen a las loterías electrónicas, las instantáneas, los bingos y las rifas. Por lo tanto, no existe una justificación para que una actividad común: el juego de lotería en sentido genérico, tenga en algunos casos como sujeto pasivo al operador y en otros al ganador del premio. ${ }^{13}$

En el caso de los juegos de bingo, rifas, sorteos "y similares", se ha dispuesto que el sujeto pasivo es el organizador del juego y en el caso de los juegos de lotería el obligado es el ganador del premio. Tan ininteligible texto lo hace inoperativo. La misma norma también señala que se grava la obtención de premios en "juegos de azar", a sabiendas de que, como se ha indicado, hay una delgada línea técnica entre un juego de azar y uno de habilidad en estos tiempos de tecnología incesante. Las deficiencias se agrandan cuando incluye como contribuyentes a los

11. El artículo 41 de la Ley de Tributación Municipal, según el texto modificado por el artículo 1 de la Ley 27675 de 2002 dispone que: "El impuesto es de periodicidad mensual. Se calcula sobre la diferencia resultante entre el ingreso total percibido en un mes por concepto de apuestas y el monto total de los premios otorgados el mismo mes".

12. El artículo 42 de la Ley de Tributación Municipal, según el texto modificado por el artículo 1 de la Ley 27924 de 2003 señala que: "La Tasa Porcentual del Impuesto a las Apuestas es de 20\%. La Tasa Porcentual del Impuesto a las Apuestas Hípicas es de 12\%".

13. El artículo 49 de la Ley de Tributación Municipal, de acuerdo con la modificación introducida por el artículo 15 del Decreto Legislativo 952 prescribe lo siguiente: "El sujeto pasivo del impuesto es la empresa o institución que realiza las actividades gravadas, así como quienes obtienen los premios. En caso de que el impuesto recaiga sobre los premios, las empresas o personas organizadoras actuarán como agentes retenedores". 
operadores del juego de pinball, juegos de video y demás juegos electrónicos sin indicar que actividades califican como tales. Si estos juegos no califican como juegos de apuesta porque el público no arriesga dinero y no se configura un contrato de juego sino uno de locación de servicios, ¿justifica una tributación especial?

\section{Los errores del Impuesto Selectivo al Consumo a los juegos de azar.}

El Impuesto Selectivo al Consumo a los juegos de azar se creó mediante el artículo 50 del Decreto Legislativo $821^{14}$ de 1996 y nació con una grosera falla de fábrica que hasta ahora lo hace constitucionalmente inexigible. En abierta violación al Principio de Reserva de Ley omitió establecer su alícuota, la cual se aprobó mediante el Decreto Supremo 095-96-EF.

En sus artículos 9 y 10 dispuso tasas diferenciadas: para las loterías, bingos, rifas y sorteos,
10\%; para los juegos de casinos, 5\%; para los eventos hípicos, 2\%; y para las máquinas tragamonedas un impuesto fijo por máquina del 15\% de una Unidad Impositiva Tributaria. Sin perjuicio de la violación sustantiva al Principio de Igualdad por un tratamiento tributario desigual injustificado, no quedaba duda de la transgresión objetiva al Principio de Reserva de Ley. Ello provocó acciones de amparo que llegaron al Tribunal Constitucional, el que obviamente las declaró fundadas. ${ }^{15}$

Posteriormente, se derogó el Impuesto Selectivo al Consumo - ISC —, a los juegos de azar, respecto de los juegos de casino y máquinas tragamonedas pues fue sustituido por el de Ley 27153 de 1999, anteriormente mencionada. ${ }^{16}$ Entonces, a dicha fecha, no existía ningún ISC exigible a los juegos de azar, pues respecto de los juegos que quedaban -loterías, bingos, rifas, sorteos y eventos hípicos-, la alícuota no había sido creada por una norma con rango de Ley.

14. El Decreto Legislativo 821, Nuevo Texto de la Ley del Impuesto General a las Ventas e Impuesto Selectivo al Consumo, dispuso lo siguiente:

Artículo $50^{\circ}$. Operaciones Gravadas. El Impuesto Selectivo al Consumo grava:

(...)

c) Los juegos de azar y apuestas, tales como loterías, bingos, rifas, sorteos, máquinas tragamonedas y otros aparatos electrónicos, casinos de juego y eventos hípicos.

$(\ldots)^{\prime \prime}$.

15. A título de ejemplo, mencionamos la Sentencia del Tribunal Constitucional recaída en el Expediente $\mathrm{N}^{\circ}$ 323-2001AA en el caso Negocios Espinoza E.I.R.L. En su fundamento 5 señala: "El artículo $74^{\circ}$ de la Constitución establece que los tributos se crean, modifican o derogan exclusivamente por ley o decreto legislativo; que el Estado, al ejercer la potestad tributaria, debe respetar los principios de reserva de la ley, y, que no surten efecto las normas tributarias dictadas en contravención de lo que establece dicho artículo. Asimismo, la norma IV del Título Preliminar del Código Tributario dispone que sólo por ley o decreto legislativo se puede crear, modificar y suprimir tributos; señalar el hecho generador de la obligación tributaria, la base para su cálculo y la alícuota. Por lo tanto, el establecimiento de la alícuota del Impuesto Selectivo al Consumo a las máquinas tragamonedas mediante el Decreto Supremo N095-96-EEF vulnera el principio de legalidad o de reserva de ley, contemplado en el precitado artículo de la Constitución".

16. El artículo 1 de la Ley 27153, Ley que regula la explotación de los juegos de casino y máquinas tragamonedas, estableció la finalidad de la ley y allí se señaló entre otros, promover el turismo receptivo y establecer el impuesto a los juegos de casino y de máquinas tragamonedas y para que no quede duda que este impuesto sustituía al inconstitucional impuesto creado por el Decreto Legislativo 821, en su Cuarta Disposición Complementaria y Final dispuso: "Modifícase el literal c) del Artículo 50 del Decreto Legislativo N821, Ley del Impuesto General a las Ventas e Impuesto Selectivo al Consumo, recogido en el Decreto Supremo N055-99-EF, Texto Único Ordenado de dicha Ley, el que quedará redactado de la siguiente manera:

"c) Los juegos de azar y apuestas, tales como loterías, bingos, rifas, sorteos y eventos hípicos".

Elimínase toda referencia a la aplicación del Impuesto Selectivo al Consumo a casinos de juego, máquinas tragamonedas y otros aparatos electrónicos, contenidas en el Título II, así como en el Apéndice IV y en cualquier otra disposición de la Ley del Impuesto General a las Ventas e Impuesto Selectivo al Consumo, contenida en el Decreto Supremo $N^{\circ} 055$ 99-EF, Texto Único Ordenado de dicha Ley". 
Posteriormente, el Poder Ejecutivo pidió facultades legislativas al Congreso para incorporar nuevamente a los juegos de casino y máquinas tragamonedas e incluir por primera vez a los juegos de apuestas online al ISC y mediante Ley autoritativa 30823, el Congreso se lo otorgó. Es así que, mediante el Decreto Legislativo 1419 del 2018 se aprobó un nuevo impuesto, pero en lugar de crear un Impuesto Selectivo al Consumidor, estableció un Impuesto a las utilidades brutas del operador, imposible de ser trasladado a los usuarios y además excluyó de este a los juegos de apuestas online. Como consecuencia de ello, al día de hoy, hay un ISC únicamente para los juegos de casino y máquinas tragamonedas, pues los otros juegos incluidos - loterías, bingos, rifas, sorteos y eventos hípicos- no tienen una alícuota exigible en la Ley y los demás juegos - apuestas online y otros juegos de apuestas presenciales- no están ni siquiera considerados.

Para mayores vicios constitucionales, la técnica tributaria establecida en este ISC es objetivamente confiscatoria. En el caso de las máquinas tragamonedas, por ejemplo, el operador tiene que pagar un impuesto fijo en función de su "ganancia bruta mensual", aun cuando el Poder Ejecutivo lo denomine "ingreso neto mensual".17 Se han fijado tres niveles de ganancia bruta. El primer nivel es cuando el ingreso mensual de una máquina tragamonedas fue de hasta 1 UIT, en cuyo caso pagará el $1.5 \%$ de 1 UIT. El segundo nivel es si el ingreso mensual fue más de 1 UIT hasta 3 UIT y pagará una cantidad fija de $7.5 \%$ de 1 UIT. Finalmente, el tercer nivel es si el ingreso mensual es superior a 3 UIT y pagará una cantidad fija de $27 \%$ de 1 UIT. Esta norma expresamente ordena pagar por cada máquina tragamonedas como mínimo el monto fijo establecido en el primer nivel de ingresos. ${ }^{18}$ Esto quiere decir que si una máquina durante un mes tuvo un ingreso equivalente al $1 \%$ de la UIT, el $100 \%$ de su ingreso será para el Estado. Y si tuvo pérdida - lo cual es usualigual tendrá que pagar ese mes a la SUNAT la suma de $1 \%$ de la UIT.

El Decreto Legislativo 1419 fue objeto de control político en la Comisión de Constitución del Congreso y esta declaró que era inconstitucional, pero aún no ha sido discutido en el Pleno. Posteriormente, fue objeto de un proceso de inconstitucionalidad que derivó en la Sentencia del Tribunal Constitucional recaída en el Expediente $\mathrm{N}^{\circ}$ 0001-2019-PI/TC que por mayoría simple también fue declarada fundada declarándose inconstitucional en su totalidad el Decreto Legislativo 1419; sin embargo, no se logró la mayoría de 5 votos para expulsarla de nuestro ordenamiento jurídico.

Los argumentos de los magistrados del Tribunal Constitucional que consideraron constitucional al Decreto Legislativo 1419 no permiten comprender su razonamiento. Uno de los temas en cuestión es si el impuesto realmente era trasladable al consumidor o en sus hechos constituye un impuesto directo al operador. A título de ejemplo, citamos el voto singular del Magistrado Espinosa-Saldaña quien justifica que sí es un impuesto al consumidor de la siguiente manera:

"16. Como es de conocimiento general, con un impuesto al consumo lo que se busca es desincentivar el desarrollo de una actividad a la compra o uso de algún bien. Entonces, no es cierto que aquí se graven las utilidades del operador de casinos y tragamonedas.

17. El artículo 4.2 del Reglamento del Impuesto Selectivo al Consumo a los juegos de casino y máquinas tragamonedas, aprobado por el Decreto Supremo №341-2018-EF dispone lo siguiente: "Tratándose de máquinas tragamonedas, el impuesto se aplica por cada máquina, según su nivel de ingreso neto mensual. El ingreso neto mensual es la diferencia entre el monto total recibido por apuestas en el mes y el monto total entregado por los premios otorgados en ese mes". Ese es el concepto de "ganancia bruta mensual".

18. El artículo 60 de la Ley del IGV e ISC ahora dice: “(...). El impuesto a pagar por cada mesa de juegos de casino o por cada máquina tragamonedas en ningún caso es inferior al monto fijo establecido para el primer nivel de ingresos netos". No interesa si el operador tuvo pérdidas, igual deberá pagar. 
Este operador no se hace cargo de este impuesto, no lo paga con sus recursos. Traslada el impuesto que se plantea al usuario, quien es la persona que lo paga, la que asume el costo de realizar una actividad que se quiere desincentivar. Estamos pues ante un impuesto al consumo, que, tal como corresponde en estos escenarios, lo paga precisamente el consumidor".

Como puede notarse, no prueba su argumento de ser trasladable al consumidor. Sólo porque el impuesto se denomina "selectivo al consumo" no lo convierte en tal. El problema es grave pues debe existir un mínimo de razonabilidad en los votos de los miembros del Tribunal Constitucional. No pueden llegar a una conclusión - a todas luces contraria a la lógica- sin explicarla. No sólo desorientan a la ciudadanía, sino que no hacen interpretación constitucional.

Como señalaba el extinto y reputado Juez de la Corte Suprema de los Estados Unidos, Antonin Scalia, "dar sentido a lo que no tiene sentido es crear un texto en lugar de interpretarlo".19

Lamentablemente ello ocurre cuando los magistrados del Tribunal Constitucional abdican de su labor de hacer justicia y anteponen prejuicios al evaluar la constitucionalidad de un impuesto. Con la metodología establecida en el Decreto Legislativo 1419 es imposible trasladar el impuesto al jugador. Pongamos el ejemplo más sencillo: el 01 de febrero de 2020, el Sr. Pérez acude a una Sala de Juego y hace una apuesta de $\mathrm{S} / 10.00$ en la máquina $\mathrm{N}^{\circ} 01$. En su primera y única jugada, el Sr. Pérez gana un premio de S/ 100.00. El Sr. Pérez se retira y durante ese mes, ningún otro jugador emplea la misma máquina. Entonces, por el período tributario del mes de febrero 2020, el operador declara una pérdida de (-100.00). Conforme al Decreto Legislativo 1419, el operador está obligado a pagarle a la SUNAT la suma de $1.5 \%$ de la UIT - S/ 66.00- por esa máquina. No hay ningún escenario posible para que al Sr. Pérez se le traslade la carga económica de ese impuesto.

\section{CONCLUSIONES}

La provisión de juegos de apuesta es una actividad económica perfectamente identificable para efecto del ejercicio del poder tributario del Estado. No existiendo, por regla general, razones para disponer tratamientos tributarios diferenciados - pero si los hubiera, se debería justificar objetivamente-y sabiendo que finalmente, el propósito es buscar una técnica tributaria adecuada para gravar la capacidad contributiva proveniente de aquellos usuarios que deciden satisfacer sus necesidades de entretenimiento con estos servicios y cubrir los costos de fiscalización requeridos por la naturaleza de esta actividad, se juzga conveniente que exista un único impuesto a la operación de juegos de apuesta en el país.

Este impuesto podría gravar las ganancias brutas del operador, entendiéndose por estas, a la diferencia entre las apuestas realizadas por los usuarios y los premios entregados a los usuarios. Este tributo debería ser deducible del Impuesto a la Renta, pero no sería necesario que se incluyan descuentos ficticios para reducir su base de cálculo, como actualmente ocurre con el Impuesto a los juegos de casino y máquinas tragamonedas. La alícuota debería tener en consideración que constituye un impuesto adicional y que no se les exige a otras actividades económicas, del que, además, el operador no podrá evitar su pago si es que se generó ganancia bruta.

Seguir creando Impuestos sin base técnica y transgrediendo groseramente nuestra Constitución sólo crea más conflictos y más distorsión de los principios constitucionales tributarios.

19. Antonin Scalia y Bryan Garner, Reading Law. The Interpretation of Legal Texts (Eagan, Minnesota: Thomson West, 2012), 134. Es una traducción libre de lo siguiente: "To give meaning to what is meaningless is to create a text rather than to interpret one". 